\title{
Book Review: Lab Culture Held Up to the Light
}

\author{
At the Bench, A Laboratory Navigator, by Kathy Barker, 1998, 460 pp., Cold Spring \\ Harbor Laboratory Press, Cold Spring Harbor, New York, ISBN 0-87969-523-4
}

\author{
Reviewed by Stephen DiNardo, University of Pennsylvania Medical School
}

Submitted January 9, 2003; Accepted January 9, 2003

I still remember it to this day: inserting the freshly cut key into the lock, hearing the tumblers click, and entering into what was entrusted to me-about 1000 square feet of lab space, with four bays and an additional microscopy room across the hall. The only problem, of course, was that it was completely empty: no people, no equipment (neither big nor small), and what I would come to realize only later, no explicit training in how to fill it. Despite this, it became filled, and mysteriously the lab was off and running. Then I discovered that the culture of the lab changes every few years as students graduate, postdoctoral fellows move on to their own (unfilled) lab spaces. How should I introduce new people to the culture of the lab? How did I do it in the first place? In the preface to At The Bench, A Laboratory Navigator (Cold Spring Harbor Press, 1998), Kathy Barker described this dilemma in a nutshell, stating that one's initial "unease could have been helped if everyone had access to something that explained the social and scientific ramifications of the new and wonderful surroundings". The book she went on to assemble does a remarkable job on just that point. It truly fills a niche.

\section{FOR WHOM?}

Barker's manual is appropriate for starting technicians, students (both undergraduate and graduate), as well as, for example, medical fellows entering a research lab for the first time. I thought it also useful for starting principal investigators "staring at headlights," like I had been. Its clarity would have been eminently helpful to my thinking in fashioning my entry-level speech to new students, technicians, and fellows. I have also recently realized I can use the book even now, some 14 years into running a lab: I gave the book to an entering student, from whom it was returned with scribbles in the margins in places where he clearly learned something, or where a point he probably already knew was particularly well-phrased and, thus, more memorable. This budding scientist had been a technician before and had already been introduced to the usual lab culture. Yet, now he was embarking along a distinct path within that culture and still found items within Barker's book quite useful ("think of every experiment as a publishable unit" was one underlined phrase).

Barker emphasized up front that she did not wish this book to take the place of the oral tradition within the lab. Rather,

DOI: $10.1187 /$ cbe.03-03-0013

Corresponding reviewer. E-mail address: sdinardo@mail.med. upenn.edu. she hoped that by breaking down the setting in which bench science takes place into its constituent parts, it would allow the initiate to frame appropriate questions for her colleagues. Thus, the book appropriately emphasizes oral information as one reads through it. This is as it should be, for it is an essential part of the lab experience that more senior persons learn to convey the "how-tos" and "whys" to others in the lab, as they themselves will need to develop this expertise as they come to oversee their own research enterprise when they move on to establish their own labs. In reading through the book, it was also evident to me that this text would be a particularly useful resource in smaller labs, where the oral tradition might be harder to hand down because there are fewer senior people and there are often gaps between the time senior people leave and junior people arrive.

\section{ORGANIZATION AND EASE OF INFORMATION RETRIEVAL}

The text is well laid out, being split into three broad sections: from the macroscopic ("Getting Oriented") down to the microscopic ("Navigating"). The initial chapters of the first section give one an idea of laboratory culture, including its hierarchy, comments on what to wear, courtesies to observe and attitudes to present, all the way to getting started at the lab bench and staying organized. These chapters are followed by a middle section where the chapters contain more specific information, such as an outline of how to set up experiments, record their outcomes, and present their conclusions. Finally, in the last section, "Navigating," the chapters outline in detail working with solutions, cells, and equipment, with information presented in effective and generally thoughtful ways. Appropriate resources with more in-depth treatments on particular topics are cited at the end of each chapter. However, as will happen, I found that some of the web site links are out of date.

\section{HIGH POINTS}

Important pieces of advice are speckled throughout most chapters: "in getting settled, do an experiment as soon as possible," "follow the published protocol," "think of each experiment as potentially publishable," "don't eliminate the controls if you do not have enough sample," "incorporate all approaches that you can," "in evaluating/interpreting an experiment's results, ask yourself, 'did the experiment work?', "' 
"know your cultured cells, microorganisms, genotypes," and, in the chapter on presentations, one reads "base the paper on the data, not the other way around," and "prepare your figures before you do any writing". I must say that I can hear myself saying, or wishing I had said half as well, just these sorts of things.

There are a few minor elements that one might disagree with. In general, the discussion of the laboratory notebook has all the appropriate admonitions and insight: "Your lab notebook... is proof of who you are as a scientist." There is, however, a comment about one's lab notebook being "owned" by the person writing in it and that a PI will generally not look at a "graduate student's or post-docs' [notebook], as this is viewed as intellectual infringement by many." I personally maintain the right to look through anyone's notes, at any time. I view this as part of their training; clear and complete notes are essential to the enterprise (as Barker stated up front). It is better for me (and them) to realize ahead of time that not enough information is being recorded, or recorded inappropriately, than for me to realize it only when I need to help troubleshoot an experiment.

Surprisingly, I did find a few typos, and also, I think, an error. The mechanisms by which intensifying screens work is described (and the fact that you do not need to place autoradiography film in the cold for exposure, unless you are using an intensifying screen), yet the use of two screens, I believe, is not described correctly (as described, the emitted, visible light off one screen cannot penetrate the filter specimen to expose the film).

However, the flaws are few, and Barker should be commended for assembling a resource that admirably accomplishes her goal: "to help lab people become familiar with their surroundings and be able, from the first day, to become independent, to know what questions to ask and why, to function as a scientist." I am now going to read her new treatise, At the Helm (Cold Spring Harbor Press, 2002). 